Chapter 7

\title{
Alzheimer Disease and Metabolism: Role of Cholesterol and Membrane Fluidity
}

Genaro G. Ortiz, Fermín P. Pacheco-Moisés,

Luis J. Flores-Alvarado, Miguel A. Macías-Islas,

Irma E. Velázquez-Brizuela,

Ana C. Ramírez-Anguiano,

Erandis D. Tórres-Sánchez,

Eddic W. Moráles-Sánchez, José A. Cruz-Ramos,

Genaro E Ortiz-Velázquez and

Fernando Cortés-Enríquez

Additional information is available at the end of the chapter

http://dx.doi.org/10.5772/54091

\section{Introduction}

Alzheimer's disease (AD) is an age-related disorder characterized by deposition of amyloid $\beta$-peptide $(\mathrm{A} \beta)$ and degeneration of neurons in brain regions such as the hippocampus, resulting in progressive cognitive dysfunction. The causes of Alzheimer's disease (AD) have not been fully discovered, there are three main hypotheses to explain the phenomenon: $a)$ The deficit of acetylcholine; $\mathrm{b}$ ) The accumulation of beta-amyloid ( $\mathrm{A} \beta$ and / or tau protein; and c) Metabolic disorders.

The clinical criteria for diagnosing AD were defined in 1984 by the NINCDS-ADRDA; (National Institute of Neurological and Communicative Disorders and Stroke; Alzheimer's Disease and Related Disorders). It states that for the diagnosis of disease is required to prove the existence of chronic and progressive cognitive impairment in adults or elderly patients, without other underlying causes that can explain this phenomenon. However, using this criterion, it is difficult to differentiate between $\mathrm{AD}$ and other causes of deterioration in early stages of the disease. 
A number of recent research has been related AD with metabolic disorders, particularly hyperglycemia and insulin resistance. The expression of insulin receptors has been demonstrated in the central nervous system neurons, preferably in the hippocampus. In these neurons, when insulin binds to its cellular receptor, promotes the activation of intracellular signaling cascades that lead to change in the expression of genes related to synaptic plasticity processes and enzymes involved in clearing the same insulin and $A \beta$. These enzymes degrading of insulin promotes the reduction of toxicity due to amyloid in animal models.

People with neuritic plaques accumulate in brain regions that correspond to brain regions in healthy people that rise in a metabolic process called aerobic glycolysis. While some regions such as prefrontal and parietal cortex, which is thought to have a role in self-recognition and control tasks, showed high levels of aerobic glycolysis, others such as the cerebellum and the hippocampal formation, believed to affect the control motor and memory, showed low levels. Brain cells use aerobic glycolysis for energy derived quickly from small amounts of glucose while obtaining the mass of its energy through a biochemical process effective to burn glucose. Since aerobic glycolysis may help the brain generate cell constituents, toxic metabolic byproducts manage and regulate programmed cell death; the findings suggest a possible link between brain function that provides energy to aerobic glycolysis and the onset of AD.

The causes of the late AD appear to be multifactorial, and cell biology studies point to cholesterol as a key factor in protein precursor of beta Amyloid (APP) processing and A $\beta$ production. An alteration in cholesterol metabolism is attractive hypotheses, thus the carriers of the Apolipoprotein E4 genes, which is involved in cholesterol metabolism, are at increased genetic risk for Alzheimer's disease. Cholesterol is a component of cell membranes and particularly is found in microdomains functionally linked to the proteolytic processing of APP. In sporadic $\mathrm{AD}$, a marked diminution of both membrane phospholipids and cholesterol has been found.

Epidemiological studies indicate that mild hypercholesterolemia may increase the risk of $\mathrm{AD}$ and decreased synthesis of cholesterol through statin administration can reduce the development of $\mathrm{AD}$. Moreover, high cellular cholesterol content has been shown to favor the production of $\mathrm{A} \beta$. Genetic studies have suggested links between AD and cholesterol control several genes including cholesterol acceptor ApoE ( $\varepsilon 4$ polymorphism). Liver $X$ receptors (LRXs) are ligand-activated transcription factors of the nuclear hormone receptor superfamily LXRs and also are expressed in the brain. LXRs stimulate the expression of genes involved in cellular cholesterol transport, regulation of lipid content of lipoproteins (apoE, lipoprotein lipase, cholesterol ester transfer protein, and phospholipid transfer protein), metabolism of fatty acids and triglycerides (sterol regulatory element binding protein 1-c, fatty acid synthase, stearoyl coenzyme A desaturase 1, and acyl coenzyme A carboxylase). Many questions remain, but as a master regulator of cholesterol homeostasis, LXR may be considered as a potential molecular target for the treatment of AD.

In summary, numerous studies on the role of cholesterol in AD suggest that high cholesterol is a risk factor for early and late $\mathrm{AD}$ development. 


\section{Dementia and pathological changes}

Dementia is a syndrome that cause cognitive and memory alterations; problems of orientation, attention, language and solving problems. Dementia involves a progressive decline in cognition that goes above and beyond the normal changes that come with age due to injuries or brain diseases. The two most common causes of dementia are AD and vascular dementia. More than $33 \%$ of women and $20 \%$ of men aged 65 year or more will develop dementia during their lifetime, and many more develop a milder form of cognitive impairment. Worldwide, the adult population is rapidly growing; prospective epidemiological studies suggest that there will be an increase of $50 \%$ of the total number of people with cognitive disorders in the next 25 years. Dementia is associated with increased mortality and disability, health care costs they mean a huge expenditure on health systems as well as a significant increase in social and economic responsibilities for caregivers and their families. With a current affection about $10 \%$ of the population over the 65 year-old Alzheimer's disease $(\mathrm{AD})$ is the most common cause of progressive dementia [1].

$\mathrm{AD}$ is a progressive neurological disorder resulting in irreversible loss of neurons, particularly in the cortex and hippocampus, accounting for about one third of dementia syndromes, with a range that varies from 42 to $81 \%$ of all dementias. The clinical findings are characterized by progressive loose of memory, loss of: judgment, decision making, physical orientation and language disorders. The diagnosis is based on neurological examination and differential diagnosis with other dementias, but the definitive diagnosis is made only by autopsy. The pathological findings at microscopic level are: neuronal loss, gliosis, neurofibrillary tangles, neuritic plaques, Hirano bodies, granulo-vacuolar degeneration of neurons and amyloid angiopathy $[2,3]$. A very early change in $\mathrm{AD}$ brain is the reduced glucose metabolism [4], and a recent analysis suggests that diabetes plays a role in the acceleration of brain aging. But, although it is known that type 2-diabetes may be associated with an increased risk of dementia, the exact mechanisms and mitigating factors still are not completely understood. The public health implications of this phenomenon are enormous. Although initially the association between type 2 diabetes and vascular dementia appeared to be more consistent than the relationship between type 2 diabetes and $\mathrm{AD}$, there are recent studies that have yielded more consistent evidence of the relationship between diabetes and $\mathrm{AD}[5,6]$.

Neuritic plaques, neurofibrillary tangles and other proteins in AD brain are glycosylated [7]. Since people with diabetes have an increased blood glucose level is plausible to suspect that they have a higher chance of having AD. Animal models of induced diabetes suggest a direct neurodegenerative effect of diabetes; most of these studies show damage in the hippocampus, an area associated with learning and memory, and first structure to be affected by the neurodegeneration of AD disease. A post-mortem study revealed that people with diabetes and ApoE 4 allele, had more neuritic plaques and neurofibrilar tangles in the hippocampus and cortex, also cerebral amyloid angiopathy, in which the associated protein $\mathrm{AD}$ disease is deposited on the walls of blood vessels in the brain. It has been shown that those with diabetes have a greater cortical atrophy, independent of 
hypertension, the blood concentration of total cholesterol, smoking, coronary heart disease and sociodemographic factors than people without the condition. Today we know that obesity increases the risk of dementia and brain atrophy. However, the molecular mechanisms that are behind metabolic disorders caused by excess body fat are not fully understood yet, especially regarding its role in neurodegenerative diseases (see Figure 1). Preliminary evidence suggests that some adipocytokines could cross the blood brain barrier, and have some function in learning and memory [8].

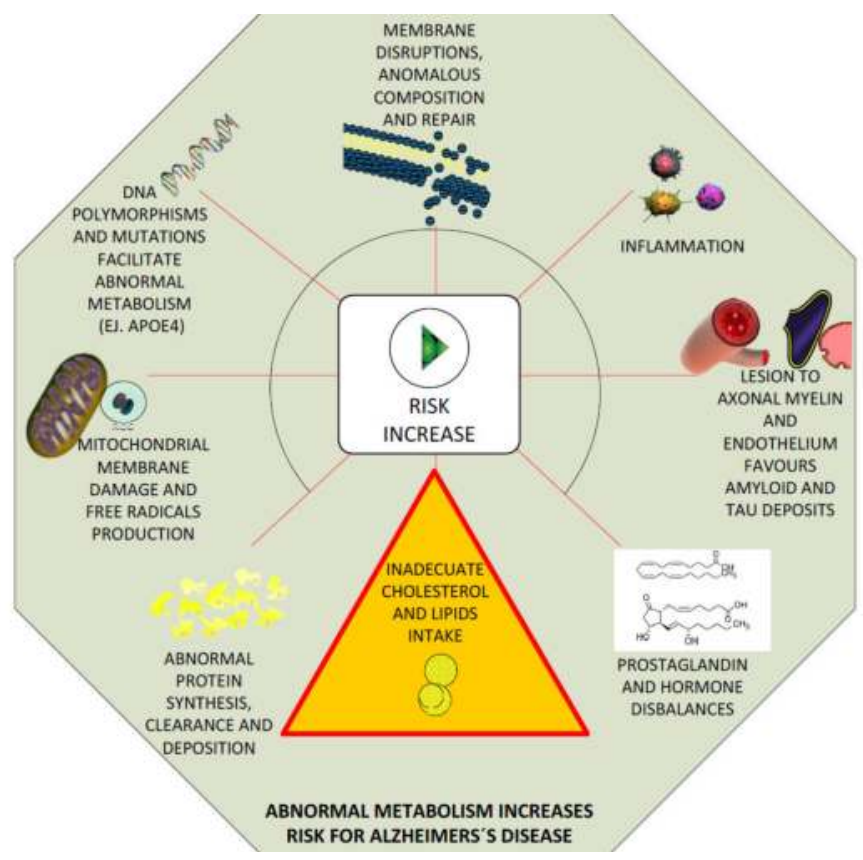

Figure 1. Abnormal metabolism increases risk for Alzheimer disease.

Recent findings from several longitudinal population studies have confirmed a link between obesity and risk of dementia. People with a body mass index (BMI) indicating obesity $(\geq 30)$ have a greater probability of developing dementia (75\%) compared with those with normal BMI (18.5 to 24.9). We must emphasize that abdominal obesity is more closely associated with dementia risk, that obesity spread throughout the body. Even for those with a healthy weight, abdominal obesity increases the risk of dementia [9].

\section{Insulin-cholesterol-AD}

Insulin signaling in the central nervous system has gained much interest for his participation in cognitive processes such as learning and memory and its possible relation to neuro- 
degenerative diseases such as Alzheimer's disease. In peripheral tissues, mainly regulates insulin metabolism energetic and cell growth. The insulin receptor and several components of its signaling pathway are abundantly distributed in the mammalian brain and their activation modulates neuronal growth and synaptic plasticity [10].

It has been suggested that some alterations in the insulin signaling appear to be responsible for cognitive deficits and play an important role in the development of AD disease. Indeed, Type II diabetes is a risk factor for developing this type of dementia. Recently it has been observed that $A \beta$, which is overproduced in $\mathrm{AD}$ disease, causes alterations in the signaling pathway of insulin, supporting the causal relationships between this condition interesting and insulin [11]. In recent years the effects of insulin in the brain have drawn attention for his participation in mental processes such as memory and learning. Insulin in the brain plays an important role in the regulation of metabolism, and alterations in their activity are directly related to metabolic diseases such as obesity, diabetes or metabolic syndrome. In the mammalian brain, insulin anorexigenic effects, induces weight loss and regulates hypothalamic control of food intake. Also regulates glucose homeostasis by stimulating peripheral neurons producing pro-opiomelacortina (POMC) and agouti-related peptide (AgRP) through the IR and PI3K $[12,13]$.

Insulin can be generated in different brain sites. It is known that insulin is produced in the beta cells of the pancreas and can enter the brain through the blood brain barrier by active transport mediated by IR. Furthermore, the presence of messenger RNA in mammalian brain neurons, suggests that insulin can be produced locally. Likewise, there has been a strict regulation of the levels of insulin and its receptor (IR) in the brain, which may suggest that insulin level in the brain does not depend exclusively on the periphery [14]. However, if the source is local cerebral insulin, peripheral or shared has not been clarified yet. The IR is very abundant in the brains of rodents and humans with the highest concentration in the olfactory bulb, the hypothalamus, pituitary gland, hippocampus, cerebral cortex and cerebellum $[15,16]$. In addition, most of the proteins of the insulin signaling pathway have expression patterns that overlap with the IR in the brain. The IR is found abundantly in the hippocampus and its expression is increased after spatial learning tasks in rodents. The IR is widely found in the synapses of the dendritic trees which regulate the release of neurotransmitters and receptor recruitment [17] (see Figure 2).

Insulin regulates glutamatergic and GABAergic receptors, through the activation of the PI3K and MAPK. It is also known that the processes of long-term potentiation (LTP) and long-term depression (LTD), are associated with the molecular events underlying the establishment of memory and learning are regulated by the activation of PI3K through Complex formation with NMDA receptors, which regulates PI3K NMDA receptor translocation to the membrane. The response of the IR is reduced by the action of glutamate and depolarization, probably involving calcium influx of $\mathrm{Ca} 2+$ and activation of Ca2+-dependent kinases (Figure 3 ). This suggests a possible role of insulin in the synaptic plasticity and modulation of neuronal activity [18-20]. 


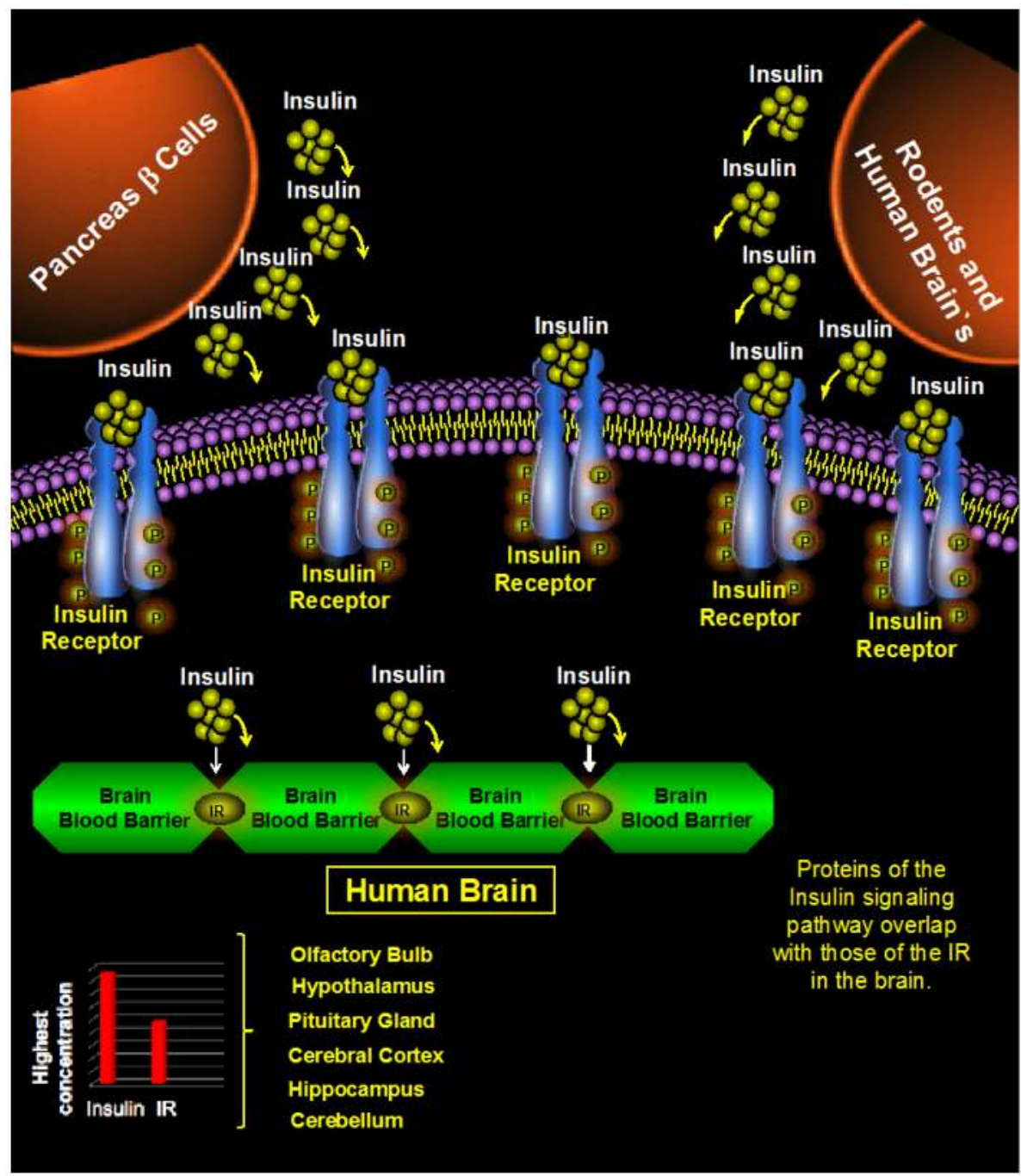

Figure 2. Insulin is produced in the Beta cells of the pancreasand enters the brain through the BBB (Brain Blood Barrier) via the IR (Insulin Receptor). Insulin levels on the brain do not depend exclusively on peripherical levels. The IR is very abundant in the brain of rodents and humans, showing its highest concentration in the following areas (in descending order): Olfactory bulb, hypothalamus, pituitary gland, cerebral cortex, hippocampus and the cerebellum. Most of the proteins involved in the insulin signaling pathway have expression patterns that overlap with the IR in the brain [125].

The presence of components via postsynaptic regions, such as mTOR, p70S6K, eIF-4E, 4EBP1 and 4EBP2 suggest the existence of the regulation of protein synthesis at synapses. Insulin regulates the levels of the postsynaptic density protein PSD-95, which binds to the NMDA receptors in the synaptic membrane, through mTOR activation and modulation of 
protein translation at synapses. Furthermore, mTOR modulates synaptic plasticity Thus, insulin not only modulates neuronal synaptic activity [21]

Different strategies can be proposed to prevent the characteristics of AD-related dysfunction of the insulin signaling pathway. An important factor is the signal transduction through Akt. Akt activity can be improved with appropriate levels of omega-3 and DHA, which can help reduce $\beta A$ levels and amyloid burden, as has been observed in transgenic mice Tg2576 regulating the activity of the enzyme IDE [22]. The loss of inhibition of GSK3 is involved in the production of neurofibrillary tangles and tau aggregation, which leads to oxidative stress, damage and toxicity in the neuronal synapses, so that GSK3 inhibitors could be used to prevent hyperphosphorylation of tau and the production of neurofibrillary tangles. Insulin has been used to improve memory and learning in healthy subjects and also in behavioral tasks in rats, suggesting a role in enhancing memory in humans, however, the actual effects of insulin on the CNS are just being elucidated $[23,24]$.

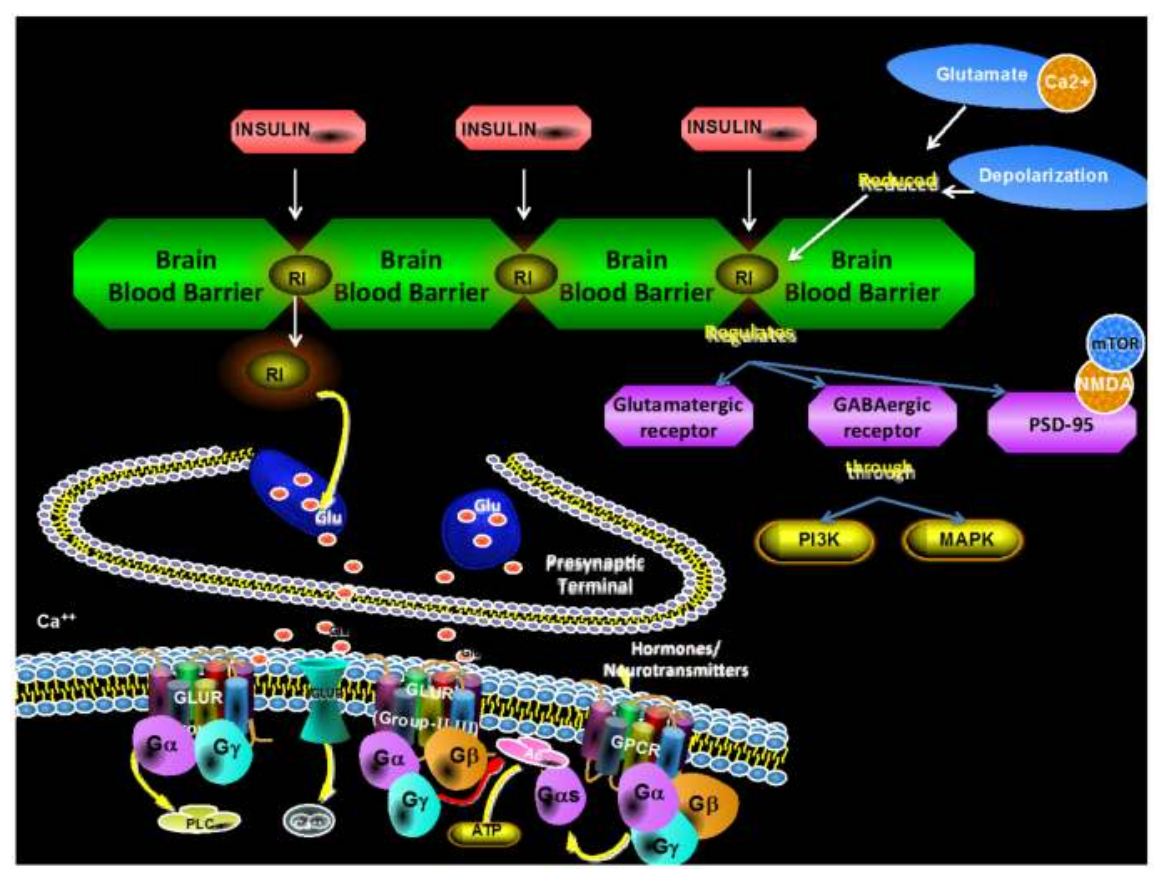

Figure 3. Insulin can enter the brain through the blood barrier by active transport mediated by IR. The IR is found abundantly in the hippocampus and synapses of dendritic trees, wich regulates the release of neurotransmitters and receptor recruitment. Insulin regulates glutamatergic and GABAergic receptors throug PI3K and MAPK [126].

Among the compounds which have been proposed as reducing agents include $\beta$ A charging the statins, which lower cholesterol levels, some peptides that prevent $\mathrm{A} \beta$ fibril formation as PBT-531 and NC-1 (a chelating metals) and modulators of the activity of the secretases as 
Bryostatin. Finally, the use of antioxidants such as vitamin E, have shown effectively to counter the effects of oxidative stress produced in the EA [25].

\section{Proteins involved in cholesterol metabolism}

Cholesterol, the most common steroid in humans, is a structural component of cell membranes and is a precursor of steroid hormones and bile salts. Since an excess of cholesterol is a major risk factor for the development of cardiovascular disease, it is essential a balance between cholesterol synthesis, uptake, and catabolism. Cholesterol is only synthesized in the liver and brain. The brain contains about $20 \%$ of total body cholesterol but only $2 \%$ of total body weight. The majority of this cholesterol is found in myelin membranes. Brain cholesterol is synthesized exclusively by de novo synthesis reaction from acetyl-CoA and acetoacetyl-CoA to form HMG-CoA. Then, is converted to mevalonate by HMG-CoA reductase, in the rate-limiting step of the process by oligodendrocytes, astrocytes and neurons [26].

After synthesis and secretion from glia via the ABCA1 transporter, cholesterol is packaged into lipoprotein particles resembling HDL. These HDL particles contain apoE. HDL is taken up into neurons through recognition of ApoE by a variety of lipoprotein receptors including the LDL receptor (LDLR); the LDL receptor related protein (LRP), the apoE receptor, as well as other lipoprotein receptors. Elimination of cholesterol from the brain occurs mainly via oxidation at the 24 and 27 positions to produce a class of compounds termed oxysterols. Water solubility of oxysterols is higher than cholesterol and diffuse across the BBB where they enter the peripheral circulation for excretion. In vitro studies showed a cholesterol shuttle from astrocytes to neurons that is mediated by apoE [27]. Virtually no cholesterol crosses the blood brain barrier from the peripheral circulation. Therefore, serum cholesterol levels have no effect on HMG-CoA reductase and its activity in the brain [28], and on total brain cholesterol levels [29]. The plasma half-life of cholesterol is several hours and fluctuates significantly according to intake. By contrast, cholesterol in the CNS is metabolized slowly, with a half life of 6 months in rats, and about 1 year in humans. In fact, changes in serum cholesterol have low impact on the CNS. Cholesterol metabolism in the brain is regulated by apoE4 and 24-hydroxylase. The rate-limiting enzyme 24-hydroxylase is uniquely expressed in the brain, and modulates the removal of cholesterol from the brain. The gene encoding this enzyme is called CYP46, and the CYP46 polymorphism was found to be associated with an increased $A \beta$ deposition and tau phosphorylation, as well as with a higher risk of late-onset $\mathrm{AD}[30,31]$. Cholesterol 24-hydroxylase (Cyp46) related to cytochrome P450, the ABC transporter (ABCA1), the receptor-associated protein to LDL (LRP) and the -2-macroglobulin. LRP1 is expressed mainly in neurons and activated astrocytes [32], and directly binds free $\mathrm{A} \beta$, and mediates its egress from the brain [33]. Furthermore, it has been suggested that $\gamma$ secretase-mediated processing of APP plays a regulatory role in brain cholesterol and apoE metabolism through LRP1 [34]. In addition, the LRP polymorphism is negatively associated with Alzheimer. The Cyp46 is a brain specific enzyme that oxidizes cholesterol to form 24 (S)-hydroxycholesterol and its function is to remove cholesterol from the brain. Moreover, statins have been linked with $\mathrm{AD}$, because the subjects medicated with them have lower 
prevalence of the disease [35]. The LRP-associated protein binds to LDL receptor very prominent in neurons. The $\alpha 2$-macroglobulin is a protein capable of binding A $\beta$ with high specificity and preventing its fibrillization [36]. $\alpha 2 \mathrm{M}$ is found in neuritic plaques in AD brain [37] and it may play a role in A $\beta$ clearance via LRP, as it is known to be able to bind other ligands and target them for internalization and degradation [38]. However, the putative role of these molecules in AD is controversial because some studies have failed to show an association between polymorphisms of $\alpha$ 2-macroglobulin and $\mathrm{AD}[39,40]$.

Studies in vitro showed that cholesterol depletion after treatment with both statins and methyl- $\beta$-cyclodextrin, which physically extracts membrane cholesterol, inhibits the generation of $\mathrm{A} \beta$ in hippocampal cells [41,42]. In transgenic AD animal models, hypercholesterolemia accelerates the development of Alzheimer's amyloid pathology [43]. Cholesterol-fed rabbits also develop changes in their brain that are typical of AD pathology [44].

Clinic-epidemiological studies suggest that increased serum cholesterol levels did not correlate substantially with AD in older ages [45,46]. However, all epidemiological studies, genetic, metabolic and laboratory show that many factors regulation of cholesterol metabolism are involved in the physiopathology of $\mathrm{AD}$. The most prevalent risk factor identified to date is the Apolipoprotein E4 (Apo-E4), which is a protein carrier of cholesterol, Apo-E exists in the brain and the periphery. Although the E4 genotype appears to confer a risk for $\mathrm{AD}$ independent of plasma levels of cholesterol, the data do not clearly discriminate whether the polymorphism of the Apo E4 contributes to Alzheimer through a direct effect on $A \beta$, or an indirect effect through involving the catabolism of cholesterol (Figure 4). The levels of 24-hydroxycholesterol (24-OHC) is increased with age in subjects with $\mathrm{AD}$, and recent studies suggest that genetic factors related to this molecule contribute to the pathogenesis of the disease [47].

Cholesterol catabolites also regulate the processing of the APP. Pharmacological inhibition of acyl-CoA:cholesterol acyltransferase (ACAT), which produces cholesterol esters, decreases A $\beta$. This is significant because the ACAT inhibitors are in development for the pharmaceutical companies for the treatment of atherosclerosis and such drugs may become useful for testing in AD. On the other hand, synthetic oxysterol, 22-hydroxycholesterol and synthetic LXR agonist reduces $A \beta$ generation in murine models of $A D$ via elevated apoE protein levels and increased lipidation of apoE, rather than through suppression of $A \beta$ generation [48]. Furthermore, LXR agonist preserves cognitive function at a dose far below required to observe decreased $A \beta$ levels [49] and $\mathrm{AD}$ neuropathology was exacerbated in mice lacking LXRs, providing further support for the central role of LXR target genes in the pathogenesis of $\mathrm{AD}$. The enzyme that catalyzes the cleavage of $\beta$ APP $\beta$-secretase is the (BACE) and their activity is particularly dependent on cholesterol levels [50] (Figure 5).

Studies on the cholesterol use in the brain of AD patients are also significant and consistent; cholesterol is removed from the brain to become $24-\mathrm{OHC}$, which appears in the plasma. The 24-OHC levels are increased in patients with AD or any other degenerative disease. The increase is probably, because cholesterol from degenerating neurons is captured and removed to maintain homeostasis. It has been shown that neurons with degenerative tangles showed increased levels of cholesterol. However, there is a striking difference between serum and 
brain levels of 24-OHC in AD, because the first increase; while the latter decrease. This perhaps reflects the decline in the number of neurons and synapses in the brains of subjects who died with AD [47]. Cholesterol is synthesized through a complex route that is blocked by a class of enzymes generically called statins. The clinical utility of statins has been demonstrated across multiple epidemiological studies, some of which have suggested that these drugs might be effective in treating AD disease. Advances in understanding the relationship between the biology of cholesterol and the production of $A \beta$ peptide, crucial in the development of amyloid plaque, will lead to new therapeutic approaches for AD disease.

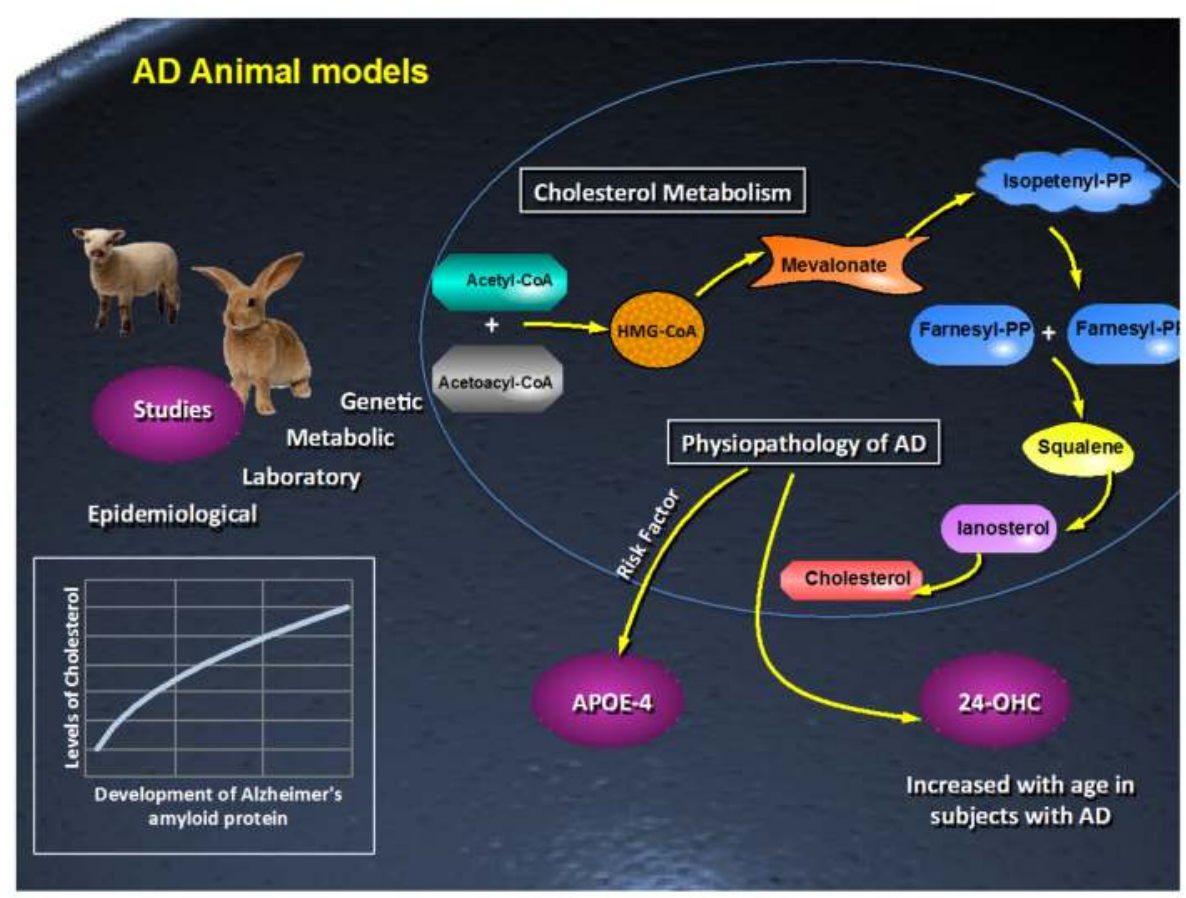

Figure 4. In Alzheimer's Disease (AD) animal models, hypercholesterolemia accelerates the development of Alzheimer's amyloid protein. Genetic, metabolic, clinical and epidemiological studies have shown that many factors involved in cholesterol's metabolism are involved in the pathophysiology of AD. The most prevalent risk factor is the APOE-4 (Apolipoprotein E4) genotype.

Statins are inhibitors of the enzyme 3-hydroxy-3-methylglutaryl coenzyme A (HMG-CoA) reductase, which converts HMG-CoA into mevalonate; this is the rate-limiting step in cholesterol biosynthesis [51]. These drugs decrease cholesterol levels about 30\% and with few adverse effects. The first statin was lovastatin was synthesized, and since then have appeared fluvastatin, pravastatin, simvastatin and atorvastatin. Simvastatin and lovastatin are administered as pro-drugs and must be activated. These drugs differ in their lipid solubility; lipophilic statins, such as pravastatin, enter cells via an ATP-dependent anion transport sys- 
tem [52]. Pravastatin was not previously thought to cross the blood-brain barrier, however, it was recently demonstrated in mice that oral pravastatin treatment results in measurable pravastatin levels in the brain [53]. Pravastatin use is associated with a reduced risk of AD $[54,55]$. Statins inhibit cholesterol synthesis but also seem to affect other processes, because they can increase apoptosis and alter neuronal proliferation. Also decrease the immune response, anti-inflammatory property that has made recently has made the proposal to treat multiple sclerosis. Also appear to inhibit bone turnover and thereby reduce osteoporosis. The probable protective effects of statins in $\mathrm{AD}$ seem stronger than any association between plasma cholesterol and disease.

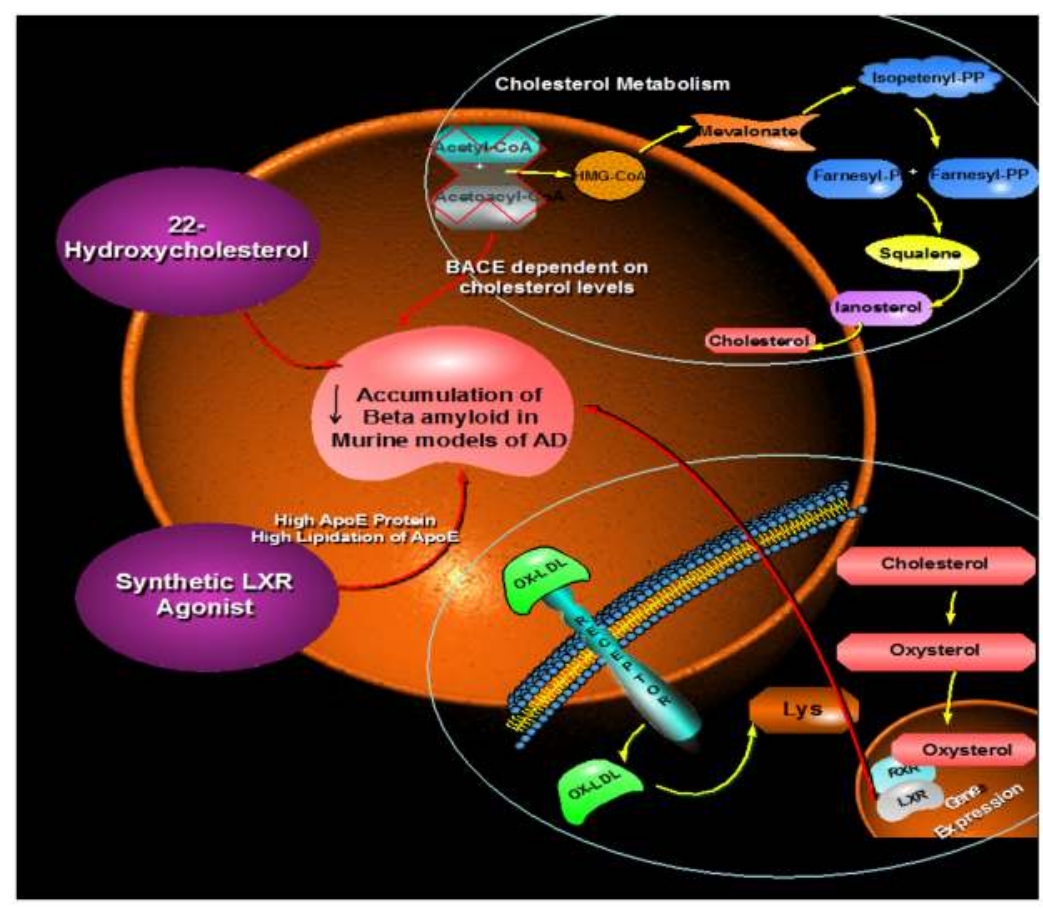

Figure 5. The inhibition of Acetyl-CoA and Acetoacyl-COA (ACAT) produces cholesterol esters and decreases Amyloid Beta (AB). Synthetic oxysterol, 22-hydroxychoresterol and synthetic LXR agonists reduce AB generation in murine models of AD via elevated ApoE protein levels and increased lipidation of ApoE [124].

Oral administration of statins, in addition to inhibiting cholesterol synthesis, also affects gene expression the mouse brain [53]. Therefore, statins may protect the brain from AD by a mechanism independent of their effect on cholesterol. In addition to inhibition of cholesterol synthesis, statins block mevalonate formation and subsequently prevent formation of isoprenoids such as famesylpyrophosphate and geranylpyrophosphate. Statins inhibit isoprenylation of proteins, including the Rho family of small GTPases, in neuronal cells [56] and cultured microglia $[57,58]$. RhoA is a monomeric G-protein that is negatively coupled to cell 
growth; prevention of RhoA isoprenylation increases neurite extension [59]. At this regard, treatment of neurons with pravastatin enhanced neurite number, length and branching, and that this effect is mediated by inhibition of mevalonate synthesis and subsequent inhibition of isoprenylation of Rho GTPases and subsequent prevention of neuritic dystrophy and deterioration [60].

Epidemiological studies have found an inverse relationship between usage of the cholesterol-lowering drugs and risk of developing $\mathrm{AD}[54,55,61]$. Statins are inhibitors of the enzyme HMG-CoA reductase, which converts HMG-CoA into mevalonate; this is the rate-limiting step in cholesterol biosynthesis [51]. However, reduction of cholesterol levels may or may not correlate with reduced risk of AD in patients taking statin drugs [62-64]. Furthermore, statin usage is associated with a decreased risk of depression and anxiety, which is not correlated with plasma cholesterol levels [65]. Oral administration of statins, in addition to inhibiting cholesterol synthesis, also affects gene expression in the mouse brain [53]. Thus, statins might prevent onset of AD by a mechanism independent of their effect on cholesterol.

Apolipoprotein E (apoE) is the major apolipoprotein in the brain and is a structural component of triglyceride-rich lipoproteins, chylomicrons, very-low-density lipoproteins (VLDL), and high-density-lipoproteins (HDL). ApoE is synthesized and secreted from astrocytes and microglia. Variation in the APOE gene sequence results in the 3 common alleles $(\varepsilon 2, \varepsilon 3$ and $\varepsilon 4)$, which can produce 6 different genotypes $(\varepsilon 2 / \varepsilon 2, \varepsilon 2 / \varepsilon 3, \varepsilon 2 / \varepsilon 4, \varepsilon 3 / \varepsilon 3$, $\varepsilon 3 / \varepsilon 4$ and $\varepsilon 4 / \varepsilon 4)$. The $\varepsilon 2, \varepsilon 3$ and $\varepsilon 4$ alleles encode three distinct forms of apoE (E2, E3 and E4) that differ in their amino acid composition at positions 112 and 158 [66]. ApoE3 seems to be the normal isoform, while apoE4 and apoE2 can each be dysfunctional [67]. Inheritance of apoE4 is associated with a greater risk of developing $\mathrm{AD}$ at an earlier age [68], whereas inheritance of apoE2 correlates with lower risk and later onset of AD [69]. individuals with the APOE $\varepsilon 4$ allele show higher levels of plasma cholesterol, especially LDL cholesterol [70]. Subjects with APOE $\varepsilon 3 / \varepsilon 4$ and $\varepsilon 4 / \varepsilon 4$ genotypes absorb cholesterol effectively and have higher non-fasting serum triglyceride values than $\varepsilon 4$ negative individuals [71,72]. A ApoE gene mutation (allele 4), the main risk factor for AD, may influence the risk of dementia more strongly among those with diabetes, in fact, findings from population studies show that people with diabetes and ApoE 4 are at greatest risk of AD compared with those without diabetes and without the ApoE 4. Although we know that people with diabetes are at increased risk of stroke, little is known about the effect of diabetes on the pathophysiology of neurodegeneration.

\section{Membrane fluidity in Alzheimer disease}

The role of the physical-chemical properties of intracellular membranous structures such as membrane fluidity in AD pathogenesis has been extensively studied. Membrane fluidity is a complex parameter, influenced both through some biophysical (temperature, electrical charges, $\mathrm{pH}$ ) and biochemical factors (protein/phospholipids ratio, phospholipids/cholester- 
ol ratio, degree of fatty acids unsaturation). It is a parameter that reflects the main membrane characteristic organization (gel or liquid crystal structure). Experiments provide consistent data about membrane fluidity relations to various cellular processes, especially membrane processes. Changes in the membrane composition and structure could alter the conformation and function of transmembranal ion channels, as well as affect the interaction of receptors and effectors, leading to altered signal transduction, handling of $\mathrm{Ca}^{\prime \prime}$, and response to exogenous stimuli [73].

Cholesterol distribution within the plasma membrane is not homogeneous: the highest level of free cholesterol inside the plasma membrane is found in cytofacial bilayer leaflet [74]. The exofacial leaflet contains substantially less cholesterol, and it is mostly condensed in lipid rafts, which are more tightly packed than nonlipid raft domains due to intermolecular hydrogen bonding involving sphingolipid and cholesterol [75]. This asymmetric distribution of cholesterol is altered by aging: it is significantly increased in exofacial leaflet with increasing age $[76,77]$. It has been reported that membrane fluidity of lipid membranes in the brain cortex of AD samples were significantly thinner (that is, had less microviscosity) than corresponding age-matched controls. This change in membrane width correlated with a $30 \%$ decrease in the ratio cholesterol/ phospholipid [78].

In our group of research we assessed the membrane fluidity in platelet submitochondrial particles and erythrocyte membranes from Mexican patients with Alzheimer disease. Submitochondrial particles are mainly constituted of inner mitochondrial membrane and are the site of oxidative phosphorylation and other enzymatic systems involved in the transport and utilization of metabolites. Membrane fluidity was estimated measuring the intramolecular excimer formation of the fluorescent probe 1,3 dipyrenylpropane incorporated in membranes. Similarly to the data reported from mitochondria in AD brains fluidity [79]., a reduced fluidity in the platelet inner mitochondrial membrane was found. It can partially be due to increased levels of lipid peroxidation [80]. Reduced membrane fluidity can diminish the activities of the enzymes of oxidative phosphorylation and other transport and receptor proteins, in as much as these enzymes are regulated by the physicochemical state of the lipid environment of the membrane. It may diminish significantly the ATP generation from the mitochondria. Interestingly, dysfunctional mitochondria and oxidative damage has been involved in Alzheimer's disease [81]. In agreement with previous reports, membrane fluidity from erythrocyte was not altered in AD [82], regardless of increased lipid oxidation in erythrocyte $\mathrm{AD}$ patients. This suggests that, in $\mathrm{AD}$, mitochondrial membranes are more sensitive to oxidative stress than erythrocytes. In contrast to platelet inner mitochondrial membrane, it has been reported an increase in fluidity in whole membranes from platelets of AD patients [83]. This increase results from the elaboration of an internal membrane compartment resembling endoplasmic reticulum that is functionally abnormal [84]. At this regard, it is worth noting that the contribution of mitochondrial membranes to the whole cell membranes in platelets could be minimized since platelets contain few mitochondria [85].

On the other hand, it has been reported that using diphenil-hexatriene (DPH) and trimethylammonium-diphenyl-hexatriene (TMA-DPH) as fluorescent probes, the membrane fluidity in mitocondrial membranes was similar in platelets from AD patients and controls [86]. That 
discrepancy with our data may be due to intrinsic differences in the populations tested, the purity of the used mitochondrial fraction and the nature of the probes used. Additionally, it's clear that the lipophilic probes are sensitive to slightly different membrane properties. For instance, DPH and TMA-DPH are rotational probes [87] and dipyrenylpropane is a lateral diffusion sensitive probe [88]. In addition, DPH partitions into the interior of the bilayer and its average location has been shown to be about $8 \AA$ from the center of the bilayer. TMA-DPH is oriented in the membrane bilayer with its positive charge localized at the lipid-water interface. Its DPH moiety is localized at about $11 \AA$ from the center of the bilayer and reports the interfacial region of the membrane [89]. Whereas dipyrenylpropane is a highly hydrophobic probe which partitions into the membrane lipid bilayer [88].

As shown in figure 1, we found a significant decrease of membrane fluidity in hippocampal neurons from AD patients compared with membranes from elderly non demented controls (Figure 6). Lower membrane fluidity in AD patients was correlated with abnormal APP processing and cognitive decline [90].

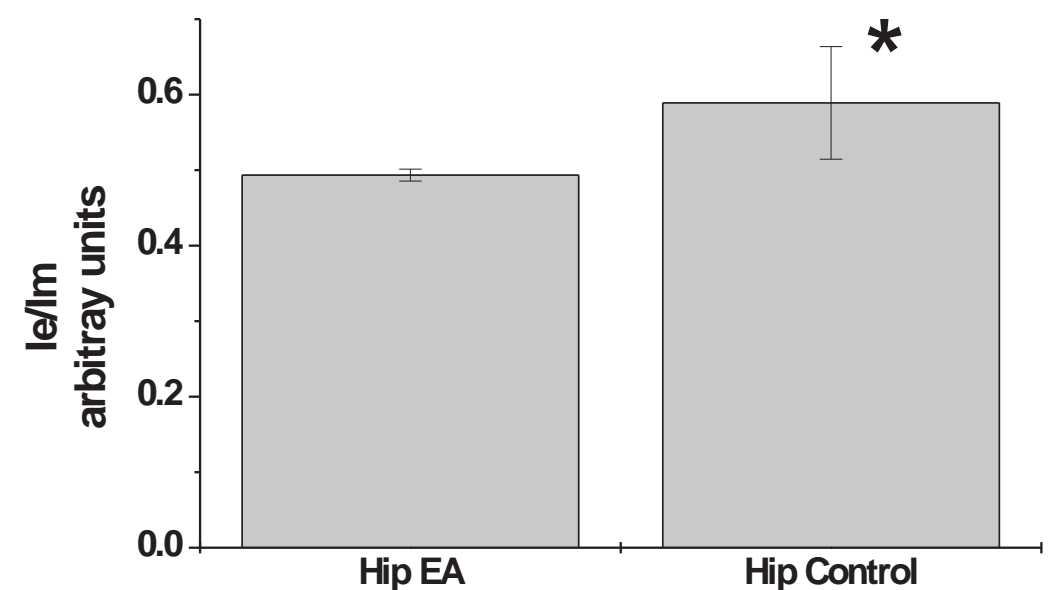

Figure 6. Excimer to monomer fluorescent ratio of dipirenylpropane on plasma membrane of hippocampus fom AD patients and aged-matched controls. The fluorescent probe was excited at $329 \mathrm{~nm}$ and emission of monomer (le) and excimer (Im) was read at 379 and $480 \mathrm{~nm}$, respectively. Intramolecular excimer formation of this probe is related with the membrane fluidity. Therefore the ratio $(\mathrm{le} / \mathrm{Im})$ is directly proportional to membrane fluidity, which is reciprocal to membrane viscosity. The data shown are mean \pm S.E.M. $* p<0.01$. 
Some strategies for the preservation of membrane fluidity include the use of polyunsaturated fatty acid (PUFAs). The brain is particularly rich in PUFAs such as eicosapentaenoic (EPA) and docosahexaenoic acids (DHA). PUFAs play an essential role in the normal development and functioning of brain [91]. Diets enriched in n-3 PUFA increased membrane fluidity, affect signal transduction and modulate gene expression for brain function [92]. Furthermore, DHA have the following effects: maintains membrane fluidity, improved synaptic and neurotransmitter functioning, enhanced learning and memory performances and displayed neuroprotective properties [93], decreased the amount of vascular A $\beta$ deposition [94] and reduced A $\beta$ burden [22]. In AD mouse model, DHA modulated APP processing by decreasing both $\alpha$ - and $\beta$-APP C-terminal fragment products and full-length APP [22]. However, caution should be taken when PUFAs are used for dietary supplementation, since DHA could be increasing oxidative stress, resulting in lipid peroxidation $[95,96]$.

Addition of cholesterol restored the membrane width to that of the age-matched control samples. Alterations in other membrane components of AD brains have also been reported. The cholesterol content in lipid rafts has been shown to contribute to the integrity of the raft structure and the functions of the rafts in signaling and membrane trafficking [97]. At this regard, it has been shown that cholesterol depletion leads to increased membrane fluidity [98] mainly in intracellular membranes [99] and reduced endocytosis, shifting sAPP shedding from $\beta$-cleavage towards $\alpha$-cleavage [63]. In fact, the cleavage of APP by $\beta$-secretase [100], occurs mainly in highly ordered membrane microdomains dispersed at the cell surface. These microdomains known as lipid rafts are enriched in cholesterol, sphingolipids and saturated phospholipids. Lipid rafts appear to be a mechanism to compartmentalize various processes on the cell surface by bringing together various receptor-mediated and signal transduction processes. The cleavage of APP by $\alpha$-secretase is done mostly in nonraft domains [101]. Furthermore, it has been shown in vitro that lowering cholesterol leads to decreased BACE-cleavage of APP [102,103] and increased $\alpha$-cleavage of APP [102].

Increased membrane fluidity due to cholesterol depletion inhibits endocytosis which might explain the observed increase of SAPP $\alpha$ and shift towards $\alpha$-secretase cleavage that happens on the cell surface. Cholesterol increase is associated with enhanced membrane stiffness possibly explaining the disrupted proximity of APP and BACE. Surprisingly this is associated with enhanced sAPP $\beta$ production, possibly explained by altered transport and endocytosis mechanisms [103]. Another explanation therefore is the direct impact of cholesterol environment upon BACE activity. In living cells, BACE seems to require intact rafts for activity, and BACE outside rafts seems to be inactive [104].

\section{Role of dietary lipids in Alzheimer disease}

Recent theories suggests that there would be an interaction between genetic predisposition and environmental factors that lead to cell death by amyloid toxicity or disruption of tau protein. Dietary lipids could be a determining factor in the difference in risk between developed and underdeveloped countries. Dietary lipids could be the primary risk factor in late- 
onset sporadic AD (LO-SAT). The critical factors seem to be the ratios of polyunsaturated fatty acids (PUFAs) to monounsaturated (MUFA), saturated fatty acids (SFA) to essential fatty acids (EFAs). These contents are modified by the APOE4 genotype [105].

Oxidation of neuronal lipid membranes could be the initiating event in the cascade of synergistic processes with subsequent expression of $\mathrm{A} \beta$ and helical filaments of hyperphosphorylated tau protein. PUFAs are important in modulating the inflammatory balance/systemic anti-inflammatory eicosanoids and fluidity and membrane function. Proinflammatory eicosanoids are derived from arachidonic acid (AA). The anti-inflammatory eicosanoids are derived from the via the n-3 EFA through DHA) and EPA. EFAs cannot be synthesized by animals and must be obtained from food. A diet rich in linoleic acid promotes proinflammatory state, while a diet rich in linolenic acid promotes inflammatory components. When lipids are exposed to free radicals begin an autoperoxidative process. This process is perpetual and changes the composition and rate of membrane lipids with loss of PUFA compared with MUFA and SFA. This causes the membrane to become less fluid and affecting the function of components, as well as of intracellular organelles and the vascular endothelium [106]. This seems to be the initial process of the cascade that culminates in neuronal death and neuropathological sequelae associated with LO-SAT. Antioxidant vitamins and vegetables may reduce the risk of AD. High levels of blood lipids are associated with atherosclerosis and diabetes, both risk factors for EA indirect. Recently it was found that the increase in LDL cholesterol, along with APOE epsilon4 genotype is associated with increased risk of AD [107].

The oxidative state of lipid membranes can have effects on neurons, at three levels:a) vascular;b) endothelial cell membrane; and c) membrane organelles.At the level of cellular membranes lipid oxidation accelerates the aggregation of amyloid which consequently decreases membrane fluidity. This also is observed with decreases of the content of MUFA and PUFA esterified to phospholipid. Interestingly, these changes are seen in brain regions affected in $\mathrm{AD}$, especially at the hippocampus. The decrease of the membrane fluidity affects the synaptic connections [108]. The EA may be preventable and treatable and possibly reversible to some extent, if the proposed hypothesis is correct. The changes in the fat composition of the diet are reflected in plasma lipids and phospholipids in the membrane of red blood cells, likewise in the neural cell membranes, especially in areas of rapid lipid turnover. A diet low of n-6 PUFA and MUFA, and an adequate amount of n-3 PUFA, but not too caloric, with antioxidants should protect neuronal damage, lipid oxidation and the inflammatory cascade and amyloid deposition.

Lipid lowering agents appear to have a protective effect, although studies are not conclusive. Statins decrease the oxidizability of LDL, with decreased levels of oxygen reactive species, anti-inflammatory effects and improve endothelial dysfunction, also increased alphasecretase activity. Increase the synthesis of LDL receptors, with decreased circulating level and reduced production of PPA.

The histological changes seen in the initial stages of $\mathrm{AD}$ confirmed that membrane lipids and inflammation are involved in the disease (Figure 7). AGE n-3/n- 6 rate has a major impact on the balance of eicosanoid metabolism inflammatory and anti-inflammatory, 
and the degree of saturation of membrane lipids and fluidity affects its function. The apoE4 genotype may influence the risk of $\mathrm{AD}$, as it is unable to protect that transports lipids from oxidation [109].

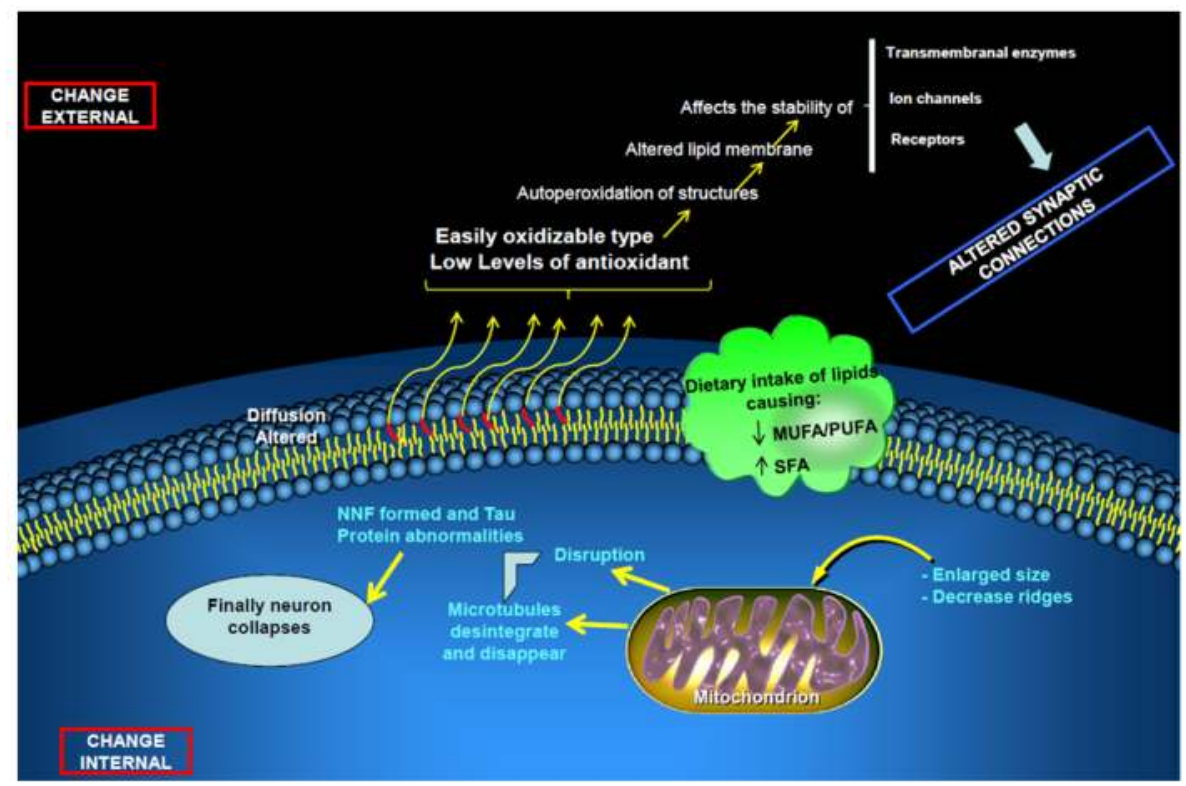

Figure 7. Cellular changes induced by lipid oxidation linked to dietary lipids. The change in dietary intake of lipids causing a low PUFA/MUFA (Polyunsaturated Fatty Acid/Monounsaturated Fatty Acids) ratio, which finally altered synaptic connections and neuron collapse [127].

\section{Membrane phospholipid metabolism}

The principal constituents of mammalian cell membranes are phospholipids, the most abundant of which is phosphatidylcholine (PC). PC biosynthesis is initiated by the phosphorylation of choline to form phosphocholine, which then combines with cytidine triphosphate (CTP) to form 5'-cytidine diphosphocholine (CDP-choline); this compound then reacts with diacylglycerol (DAG) to produce PC [110]. The rate at which cells form PC is affected by the availability of its precursors. Thus, uridine or cytidine increase CTP levels [111]; availability of CTP levels in turn can be rate-limiting in the syntheses of CDP-choline [112] and PC [113]; and DAG levels can control the conversion of CDP-choline to $\mathrm{PC}$ [114]. AD is also associated with abnormal metabolism of membrane phospho- 
lipids. Alterations in the metabolism of the phospholipids phosphatidylcholine (PC) have been detected in the cerebrospinal fluid of AD patients [115]. Neural membrane glycerophospholipids, particularly ethanolamine plasmalogens, are markedly decreased in autopsy samples from AD brain compared to age-matched control brain [116]. This decrease in glycerophospholipids is accompanied by a marked elevation in phospholipid degradation metabolites such as glycerophosphocholine, phosphocholine, and phosphoethanolamine [117]. Furthermore, marked increases have been reported in levels of prostaglandins and lipid peroxides in AD brain $[118,119]$. The marked changes observed in phospholipids and their catabolic products may be coupled to the elevated activities of lipolytic enzymes in AD brain [120]. Moreover, cortices of AD patients have decreased levels of PC and phosphatidylethanolamine, compared with age-matched controls [116]. PC synthesis is regulated by levels of its precursors [113,114]; therefore, stimulation of PC synthesis by increasing precursor levels prevents the disruption in normal phospholipid metabolism caused by AD. Furthermore, increasing cell membrane synthesis may have morphological consequences for the cell. For instance, dendritic atrophy and loss occur in mouse models of $\mathrm{AD}[121,122]$ and dystrophic neurites are observed in human cases of $\mathrm{AD}[123]$

\section{Concluding remarks}

Data from a series of biochemical, genetic, epidemiological studies and others exhibited that cholesterol is a key factor in APP processing and A $\beta$ production. For instance, high cholesterol levels are linked to increased $A \beta$ generation and deposition. It appears that there are many different ways in which abnormalities in cholesterol metabolism can affect the development of AD. Some polymorphisms in genes involved in cholesterol catabolism and transport have been associated with an increased level of $\mathrm{A} \beta$ and are therefore potential risk factors for the disease. The best known of these genes is apoE4, which is the major genetic risk factor known for late-onset AD. Other genes implicated include cholesterol 24-hydroxylase (Cyp46), the LDL receptor related protein, the cholesterol transporter ABCA1, acyl-CoA:cholesterol acetyl transferase, and the LDL receptor. Then, we may conclude that what is bad for the heart is bad for the brain. We must pay attention to risk factors associated with heart disease to prevent Alzheimer's disease also. Considerable interest has also arisen regarding the effects of lifestyle interventions such as exercise and dietary/nutriceutical manipulations.

\section{Acknowledgements}

We dedicate this paper to Dr. Pedro Garzón de la Mora; who was for some of us a guide, and showed us to lose ourselves in the wonderful jungle of Biochemistry. 


\section{Author details}

Genaro G. Ortiz ${ }^{1 *}$, Fermín P. Pacheco-Moisés², Luis J. Flores-Alvarado ${ }^{3}$, Miguel A. Macías-Islas ${ }^{4}$ Irma E. Velázquez-Brizuela ${ }^{5}$, Ana C. Ramírez-Anguiano², Erandis D. Tórres-Sánchez ${ }^{1}$, Eddic W. Moráles-Sánchez ${ }^{1}$, José A. Cruz-Ramos ${ }^{1}$, Genaro E Ortiz-Velázquez ${ }^{1}$ and Fernando Cortés-Enríquez ${ }^{1}$

*Address all correspondence to: genarogabriel@yahoo.com

1 Lab. Estrés Oxidativo-Mitocondria \& Enfermedad, Centro de Investigación Biomédica de Occidente. Instituto Mexicano del Seguro Social (IMSS). Guadalajara, Jalisco, México

2 Dpto. de Química. CUCEI, Universidad de Guadalajara. Guadalajara, Jalisco, México

3 Dpto. de Bioquímica. CUCS, Universidad de Guadalajara. Guadalajara, Jalisco, México

4 Depto. de Neurología. UMAE,HE- IMSS. Guadalajara, Jalisco, México

5 OPD-IJC-SSA- Jalisco. Guadalajara, Jalisco, México

\section{References}

[1] Reitz C, Carol Brayne \& Richard Mayeux Epidemiology of Alzheimer disease. Nature Reviews Neurology 7, 137-152.

[2] Brookmeyer R, Johnson E, Ziegler-Graham K, Arrighi HM: Forecasting the global burden of Alzheimer's disease. Alzheimers Dement 2007, 3:186-191.

[3] Tiraboschi P, Hansen LA, Thal LJ, Corey-Bloom J (June 2004). The importance of neuritic plaques and tangles to the development and evolution of AD. Neurology 62 (11): pp. 1984-9

[4] L. Mosconi, Brain glucose metabolism in the early and specific diagnosis of Alzheimer's disease. FDG-PET studies in MCI and AD. Eur J Nucl Med Mol Imaging 2005: (32) $486-510$.

[5] R. Peila, B.L. Rodriguez, L.J. Launer, Type 2 diabetes, APOE gene, and the risk for dementia and related pathologies: The Honolulu-Asia Aging Study. Diabetes 2002: (51) 1256-1262.

[6] Han W, Li C Linking type 2 diabetes and Alzheimer's disease. Proc Natl Acad Sci U S A. 2010 Apr 13;107(15):6557-8.

[7] T. Dyrks, A. Weidemann, G. Multhaup, J.M. Salbaum, H.G. Lemaire, J. Kang, B. Muller-Hill, C.L. Masters, K. Beyreuther, Identification, transmembrane orientation and 
biogenesis of the amyloid A4 precursor of Alzheimer's disease. EMBO J 1988:(7) 949-957.

[8] K. Kos, A.L. Harte, N.F. da Silva, A. Tonchev, G. Chaldakov, S. James, D.R. Snead, B. Hoggart, J.P. O'Hare, P.G. McTernan, S. Kumar, Adiponectin and resistin in human cerebrospinal fluid and expression of adiponectin receptors in the human hypothalamus. J Clin Endocrinol Metab 2007:(92) 1129-1136.

[9] R.A. Whitmer, E.P. Gunderson, C.P. Quesenberry, Jr., J. Zhou, K. Yaffe, Body mass index in midlife and risk of Alzheimer disease and vascular dementia. Curr Alzheimer Res 2007:(4) 103-109. J Neurochem. 2005 Aug;94(4):1158-66.

[10] van der Heide LP, Kamal A, Artola A, Gispen WH, Ramakers GM. Insulin modulates hippocampal activity-dependent synaptic plasticity in a N-methyl-d-aspartate receptor and phosphatidyl-inositol-3-kinase-dependent manner.

[11] Son SM, Song H, Byun J, Park KS, Jang HC, Park YJ, Mook-Jung I. Altered APP Processing in Insulin-Resistant Conditions Is Mediated by Autophagosome Accumulation via the Inhibition of Mammalian Target of Rapamycin Pathway. Diabetes. 2012 Jul 24.

[12] Plum L, Belgardt BF, Brüning JC. Central insulin action in energy and glucose homeostasis. J Clin Invest 2006; 116(7): 1761-1766

[13] Pardini AW, Nguyen HT, Figlewicz DP, Baskin DG, Williams DL, Kim F, Schwartz MW. Distribution of insulin receptor substrate-2 in brain areas involved in energy homeostasis. Brain Res 2006; 1112(1): 169-178.

[14] Abbott MA, Wells DG, Fallon JR. The insulin receptor tyrosine kinase substrate p58/53 and the insulin receptor are components of CNS synapses. J Neurosci 1999; 19(17): 7300-7308.

[15] Gerozissis K. Brain insulin, energy and glucose homeostasis; genes, environment and metabolic pathologies. Eur J Pharmacol 2008; 585(1): 38-49.

[16] Gasparini L, Netzer WJ, Greengard P, Xu H. Does insulin dysfunction play a role in Alzheimer's disease? Trends Pharmacol Sci 2002; 23(6): 288-293.

[17] Wei Y, Williams JM, Dipace C, Sung U, Javitch JA, Galli A, Saunders C. Dopamine transporter activity mediates amphetamine-induced inhibition of Akt through a Ca2+/calmodulin-dependent kinase II-dependent mechanism. Mol Pharmacol 2007; 71(3): 835-842

[18] Man HY, Wang Q, Lu WY, Ju W, Ahmadian G, Liu L, D’Souza S, Wong TP, Taghibiglou C, Lu J, Becker LE, Pei L, Liu F, Wymann MP, MacDonald JF, Wang YT. Activation of PI3-Kinase is required for AMPA receptor insertion during LTP of mEPSCs in cultured hippocampal neurons. Neuron 2003; 38(4): 611-624. 
[19] Zhao WQ, De Felice FG, Fernández S, Chen H, Lambert MP, Quon MJ, Krafft GA, Klein WL. Amyloid beta oligomers induce impairment of neuronal insulin receptors. FASEB J 2008; 22(1): 246-260.

[20] Nelson T, Alkon D. Insulin and cholesterol pathways in neuronal function, memory and neurodegeneration. Biochem Soc Trans 2005; 33(Pt 5): 1033-1036.

[21] Tang SJ, Reis G, Kang H, Gingras AC, Sonenberg N, Schuman EM. A rapamycin-sensitive signaling pathway contributes to long-term synaptic plasticity in the hippocampus. Proc Natl Acad Sci USA 2002; 99(1): 467-472.

[22] Lim GP, Calon F, Morihara T, Yang F, Teter B, Ubeda O, Salem N Jr, Frautschy SA, Cole GM. A diet enriched with the omega-3 fatty acid docosahexaenoic acid reduces amyloid burden in an aged Alzheimer mouse model. J Neurosci 2005; 25(12): 3032-3040.

[23] 2002; 22(22): 9785-9793. 45. Kern W, Peters A, Fruehwald-Schultes B, Deininger E, Born J, Fehm HL. Improving influence of insulin on cognitive functions in humans. Neuroendocrinology 2001; 74(4): 270-280

[24] Park CR, Seeley RJ, Craft S, Woods SC. Intracerebroventricular insulin enhances memory in a passive-avoidance task. Physiol Behav 2000; 68(4): 509-514.

[25] Blennow K, de Leon MJ, Zetterberg H. Alzheimer's disease. Lancet 2006; 368(9533): 387-403.

[26] J.M. Dietschy, S.D. Turley, Cholesterol metabolism in the brain. Curr Opin Lipidol 2001:(12) 105-112.

[27] O. Levi, D. Lutjohann, A. Devir, K. von Bergmann, T. Hartmann, D.M. Michaelson, Regulation of hippocampal cholesterol metabolism by apoE and environmental stimulation. J Neurochem 2005:(95) 987-997.

[28] H. Jurevics, J. Hostettler, C. Barrett, P. Morell, A.D. Toews, Diurnal and dietary-induced changes in cholesterol synthesis correlate with levels of mRNA for HMG-CoA reductase. J Lipid Res 2000:(41) 1048-1054.

[29] C. Kirsch, G.P. Eckert, A.R. Koudinov, W.E. Muller, Brain cholesterol, statins and Alzheimer's Disease. Pharmacopsychiatry 2003:(36 Suppl 2) S113-119.

[30] I. Bjorkhem, D. Lutjohann, U. Diczfalusy, L. Stahle, G. Ahlborg, J. Wahren, Cholesterol homeostasis in human brain: turnover of 24S-hydroxycholesterol and evidence for a cerebral origin of most of this oxysterol in the circulation. J Lipid Res 1998:(39) 1594-1600.

[31] A. Papassotiropoulos, J.R. Streffer, M. Tsolaki, S. Schmid, D. Thal, F. Nicosia, V. Iakovidou, A. Maddalena, D. Lutjohann, E. Ghebremedhin, T. Hegi, T. Pasch, M. Traxler, A. Bruhl, L. Benussi, G. Binetti, H. Braak, R.M. Nitsch, C. Hock, Increased brain betaamyloid load, phosphorylated tau, and risk of Alzheimer disease associated with an intronic CYP46 polymorphism. Arch Neurol 2003:(60) 29-35. 
[32] G.W. Rebeck, S.D. Harr, D.K. Strickland, B.T. Hyman, Multiple, diverse senile plaque-associated proteins are ligands of an apolipoprotein E receptor, the alpha 2-macroglobulin receptor/low-density-lipoprotein receptor-related protein. Ann Neurol 1995:(37) 211-217.

[33] M. Shibata, S. Yamada, S.R. Kumar, M. Calero, J. Bading, B. Frangione, D.M. Holtzman, C.A. Miller, D.K. Strickland, J. Ghiso, B.V. Zlokovic, Clearance of Alzheimer's amyloid-ss(1-40) peptide from brain by LDL receptor-related protein-1 at the bloodbrain barrier. J Clin Invest 2000:(106) 1489-1499.

[34] Q. Liu, C.V. Zerbinatti, J. Zhang, H.S. Hoe, B. Wang, S.L. Cole, J. Herz, L. Muglia, G. $\mathrm{Bu}$, Amyloid precursor protein regulates brain apolipoprotein $\mathrm{E}$ and cholesterol metabolism through lipoprotein receptor LRP1. Neuron 2007:(56) 66-78.

[35] M.D. Haag, A. Hofman, P.J. Koudstaal, B.H. Stricker, M.M. Breteler, Statins are associated with a reduced risk of Alzheimer disease regardless of lipophilicity. The Rotterdam Study. J Neurol Neurosurg Psychiatry 2009:(80) 13-17.

[36] S.R. Hughes, O. Khorkova, S. Goyal, J. Knaeblein, J. Heroux, N.G. Riedel, S. Sahasrabudhe, Alpha2-macroglobulin associates with beta-amyloid peptide and prevents fibril formation. Proc Natl Acad Sci U S A 1998:(95) 3275-3280.

[37] J. Bauer, S. Strauss, U. Schreiter-Gasser, U. Ganter, P. Schlegel, I. Witt, B. Yolk, M. Berger, Interleukin-6 and alpha-2-macroglobulin indicate an acute-phase state in Alzheimer's disease cortices. FEBS Lett 1991:(285) 111-114.

[38] W. Borth, Alpha 2-macroglobulin, a multifunctional binding protein with targeting characteristics. FASEB J 1992:(6) 3345-3353.

[39] D. Blacker, M.A. Wilcox, N.M. Laird, L. Rodes, S.M. Horvath, R.C. Go, R. Perry, B. Watson, Jr., S.S. Bassett, M.G. McInnis, M.S. Albert, B.T. Hyman, R.E. Tanzi, Alpha-2 macroglobulin is genetically associated with Alzheimer disease. Nat Genet 1998:(19) 357-360.

[40] E.A. Rogaeva, S. Premkumar, J. Grubber, L. Serneels, W.K. Scott, T. Kawarai, Y. Song, D.L. Hill, S.M. Abou-Donia, E.R. Martin, J.J. Vance, G. Yu, A. Orlacchio, Y. Pei, M. Nishimura, A. Supala, B. Roberge, A.M. Saunders, A.D. Roses, D. Schmechel, A. Crane-Gatherum, S. Sorbi, A. Bruni, G.W. Small, P.M. Conneally, J.L. Haines, F. Van Leuven, P.H. St George-Hyslop, L.A. Farrer, M.A. Pericak-Vance, An alpha-2-macroglobulin insertion-deletion polymorphism in Alzheimer disease. Nat Genet 1999:(22) 19-22.

[41] M. Simons, P. Keller, B. De Strooper, K. Beyreuther, C.G. Dotti, K. Simons, Cholesterol depletion inhibits the generation of beta-amyloid in hippocampal neurons. Proc Natl Acad Sci U S A 1998:(95) 6460-6464.

[42] D.S. Howland, S.P. Trusko, M.J. Savage, A.G. Reaume, D.M. Lang, J.D. Hirsch, N. Maeda, R. Siman, B.D. Greenberg, R.W. Scott, D.G. Flood, Modulation of secreted be- 
ta-amyloid precursor protein and amyloid beta-peptide in brain by cholesterol. J Biol Chem 1998:(273) 16576-16582.

[43] L.M. Refolo, B. Malester, J. LaFrancois, T. Bryant-Thomas, R. Wang, G.S. Tint, K. Sambamurti, K. Duff, M.A. Pappolla, Hypercholesterolemia accelerates the Alzheimer's amyloid pathology in a transgenic mouse model. Neurobiol Dis 2000:(7) 321-331.

[44] D.L. Sparks, Y.M. Kuo, A. Roher, T. Martin, R.J. Lukas, Alterations of Alzheimer's disease in the cholesterol-fed rabbit, including vascular inflammation. Preliminary observations. Ann N Y Acad Sci 2000:(903) 335-344.

[45] A.G. Mainous, 3rd, S.L. Eschenbach, B.J. Wells, C.J. Everett, J.M. Gill, Cholesterol, transferrin saturation, and the development of dementia and Alzheimer's disease: results from an 18-year population-based cohort. Fam Med 2005:(37) 36-42.

[46] M.M. Mielke, P.P. Zandi, M. Sjogren, D. Gustafson, S. Ostling, B. Steen, I. Skoog, High total cholesterol levels in late life associated with a reduced risk of dementia. Neurology 2005:(64) 1689-1695.

[47] V. Leoni, C. Caccia, Oxysterols as biomarkers in neurodegenerative diseases. Chem Phys Lipids 2011:(164) 515-524.

[48] R.P. Koldamova, I.M. Lefterov, M. Staufenbiel, D. Wolfe, S. Huang, J.C. Glorioso, M. Walter, M.G. Roth, J.S. Lazo, The liver X receptor ligand T0901317 decreases amyloid beta production in vitro and in a mouse model of Alzheimer's disease. J Biol Chem 2005:(280) 4079-4088.

[49] D.R. Riddell, H. Zhou, T.A. Comery, E. Kouranova, C.F. Lo, H.K. Warwick, R.H. Ring, Y. Kirksey, S. Aschmies, J. Xu, K. Kubek, W.D. Hirst, C. Gonzales, Y. Chen, E. Murphy, S. Leonard, D. Vasylyev, A. Oganesian, R.L. Martone, M.N. Pangalos, P.H. Reinhart, J.S. Jacobsen, The LXR agonist TO901317 selectively lowers hippocampal Abeta42 and improves memory in the Tg2576 mouse model of Alzheimer's disease. Mol Cell Neurosci 2007:(34) 621-628.

[50] N. Zelcer, P. Tontonoz, Liver X receptors as integrators of metabolic and inflammatory signaling. J Clin Invest 2006:(116) 607-614.

[51] B.A. Hamelin, J. Turgeon, Hydrophilicity/lipophilicity: relevance for the pharmacology and clinical effects of HMG-CoA reductase inhibitors. Trends Pharmacol Sci 1998: (19) 26-37.

[52] K. Nezasa, K. Higaki, M. Takeuchi, M. Nakano, M. Koike, Uptake of rosuvastatin by isolated rat hepatocytes: comparison with pravastatin. Xenobiotica 2003:(33) 379-388.

[53] L.N. Johnson-Anuna, G.P. Eckert, J.H. Keller, U. Igbavboa, C. Franke, T. Fechner, M. Schubert-Zsilavecz, M. Karas, W.E. Muller, W.G. Wood, Chronic administration of statins alters multiple gene expression patterns in mouse cerebral cortex. J Pharmacol Exp Ther 2005:(312) 786-793. 
[54] B. Wolozin, W. Kellman, P. Ruosseau, G.G. Celesia, G. Siegel, Decreased prevalence of Alzheimer disease associated with 3-hydroxy-3-methyglutaryl coenzyme A reductase inhibitors. Arch Neurol 2000:(57) 1439-1443.

[55] K. Rockwood, S. Kirkland, D.B. Hogan, C. MacKnight, H. Merry, R. Verreault, C. Wolfson, I. McDowell, Use of lipid-lowering agents, indication bias, and the risk of dementia in community-dwelling elderly people. Arch Neurol 2002:(59) 223-227.

[56] S. Pedrini, T.L. Carter, G. Prendergast, S. Petanceska, M.E. Ehrlich, S. Gandy, Modulation of statin-activated shedding of Alzheimer APP ectodomain by ROCK. PLoS Med 2005:(2) e18.

[57] X. Bi, M. Baudry, J. Liu, Y. Yao, L. Fu, F. Brucher, G. Lynch, Inhibition of geranylgeranylation mediates the effects of 3-hydroxy-3-methylglutaryl (HMG)-CoA reductase inhibitors on microglia. J Biol Chem 2004:(279) 48238-48245.

[58] A. Cordle, G. Landreth, 3-Hydroxy-3-methylglutaryl-coenzyme A reductase inhibitors attenuate beta-amyloid-induced microglial inflammatory responses. J Neurosci 2005:(25) 299-307.

[59] A. Sebok, N. Nusser, B. Debreceni, Z. Guo, M.F. Santos, J. Szeberenyi, G. Tigyi, Different roles for RhoA during neurite initiation, elongation, and regeneration in PC12 cells. J Neurochem 1999:(73) 949-960.

[60] A.M. Pooler, S.C. Xi, R.J. Wurtman, The 3-hydroxy-3-methylglutaryl co-enzyme A reductase inhibitor pravastatin enhances neurite outgrowth in hippocampal neurons. J Neurochem 2006:(97) 716-723.

[61] E. Zamrini, G. McGwin, J.M. Roseman, Association between statin use and Alzheimer's disease. Neuroepidemiology 2004:(23) 94-98.

[62] G.P. Eckert, Manipulation of lipid rafts in neuronal cells. The Open Biology Journal 2010:(3) 1874-1967.

[63] B. Wolozin, Cholesterol and the biology of Alzheimer's disease. Neuron 2004:(41) 7-10.

[64] W.G. Wood, F. Schroeder, U. Igbavboa, N.A. Avdulov, S.V. Chochina, Brain membrane cholesterol domains, aging and amyloid beta-peptides. Neurobiol Aging 2002: (23) 685-694.

[65] Y. Young-Xu, K.A. Chan, J.K. Liao, S. Ravid, C.M. Blatt, Long-term statin use and psychological well-being. J Am Coll Cardiol 2003:(42) 690-697.

[66] V.I. Zannis, J.L. Breslow, Human very low density lipoprotein apolipoprotein E isoprotein polymorphism is explained by genetic variation and posttranslational modification. Biochemistry 1981:(20) 1033-1041.

[67] Mahley RW, Rall SC: APOLIPOPROTEIN E: Far More Than a Lipid Transport Protein. Annu Rev Genomics Hum Genet 2000, 1:507-537. 
[68] W.J. Strittmatter, A.D. Roses, Apolipoprotein E and Alzheimer disease. Proc Natl Acad Sci U S A 1995:(92) 4725-4727.

[69] E.H. Corder, A.M. Saunders, N.J. Risch, W.J. Strittmatter, D.E. Schmechel, P.C. Gaskell, Jr., J.B. Rimmler, P.A. Locke, P.M. Conneally, K.E. Schmader, et al., Protective effect of apolipoprotein E type 2 allele for late onset Alzheimer disease. Nat Genet 1994:(7) 180-184.

[70] Y. Song, M.J. Stampfer, S. Liu, Meta-analysis: apolipoprotein E genotypes and risk for coronary heart disease. Ann Intern Med 2004:(141) 137-147.

[71] A. Tammi, T. Ronnemaa, L. Rask-Nissila, T.A. Miettinen, H. Gylling, L. Valsta, J. Viikari, I. Valimaki, O. Simell, Apolipoprotein E phenotype regulates cholesterol absorption in healthy 13-month-old children--The STRIP Study. Pediatr Res 2001:(50) 688-691.

[72] A. Tammi, T. Ronnemaa, J. Viikari, E. Jokinen, H. Lapinleimu, C. Ehnholm, O. Simell, Apolipoprotein E4 phenotype increases non-fasting serum triglyceride concentration in infants - the STRIP study. Atherosclerosis 2000:(152) 135-141.

[73] P.A. Janmey, P.K. Kinnunen, Biophysical properties of lipids and dynamic membranes. Trends Cell Biol 2006:(16) 538-546.

[74] Eckert GP, Wood WG, Muller WE (2005) Statins: drugs for Alzheimer's disease? J Neural Transm.

[75] Y. Barenholz, Sphingomyelin and cholesterol: from membrane biophysics and rafts to potential medical applications. Subcell Biochem 2004:(37) 167-215.

[76] U. Igbavboa, N.A. Avdulov, F. Schroeder, W.G. Wood, Increasing age alters transbilayer fluidity and cholesterol asymmetry in synaptic plasma membranes of mice. J Neurochem 1996:(66) 1717-1725.

[77] Wood W, Eckert GP, Igbavboa U, Muller WE (2003) Amyloid beta-protein interactions with membranes and cholesterol: causes or casualties of Alzheimer's disease. Biochim Biophys Acta 1610:281-290.

[78] R.P. Mason, W.J. Shoemaker, L. Shajenko, T.E. Chambers, L.G. Herbette, Evidence for changes in the Alzheimer's disease brain cortical membrane structure mediated by cholesterol. Neurobiol Aging 1992:(13) 413-419.

[79] P. Mecocci, A. Cherubini, M.F. Beal, R. Cecchetti, F. Chionne, M.C. Polidori, G. Romano, U. Senin, Altered mitochondrial membrane fluidity in AD brain. Neurosci Lett 1996:(207) 129-132.

[80] G.G. Ortiz, F. Pacheco-Moises, M. El Hafidi, A. Jimenez-Delgado, M.A. Macias-Islas, S.A. Rosales Corral, A.C. de la Rosa, V.J. Sanchez-Gonzalez, E.D. Arias-Merino, I.E. Velazquez-Brizuela, Detection of membrane fluidity in submitochondrial particles of platelets and erythrocyte membranes from Mexican patients with Alzheimer disease 
by intramolecular excimer formation of 1,3 dipyrenylpropane. Dis Markers 2008:(24) 151-156.

[81] E. Bonilla, K. Tanji, M. Hirano, T.H. Vu, S. DiMauro, E.A. Schon, Mitochondrial involvement in Alzheimer's disease. Biochim Biophys Acta 1999:(1410) 171-182.

[82] I. Hajimohammadreza, M.J. Brammer, S. Eagger, A. Burns, R. Levy, Platelet and erythrocyte membrane changes in Alzheimer's disease. Biochim Biophys Acta 1990: (1025) 208-214.

[83] G.S. Zubenko, U. Kopp, T. Seto, L.L. Firestone, Platelet membrane fluidity individuals at risk for Alzheimer's disease: a comparison of results from fluorescence spectroscopy and electron spin resonance spectroscopy. Psychopharmacology (Berl) 1999: (145) $175-180$.

[84] G.S. Zubenko, I. Malinakova, B. Chojnacki, Proliferation of internal membranes in platelets from patients with Alzheimer's disease. J Neuropathol Exp Neurol 1987:(46) 407-418.

[85] M.H. Fukami, L. Salganicoff, Isolation and properties of human platelet mitochondria. Blood 1973:(42) 913-918.

[86] S.M. Cardoso, M.T. Proenca, S. Santos, I. Santana, C.R. Oliveira, Cytochrome c oxidase is decreased in Alzheimer's disease platelets. Neurobiol Aging 2004:(25) 105-110.

[87] M. Ameloot, H. Hendrickx, W. Herreman, H. Pottel, F. Van Cauwelaert, W. van der Meer, Effect of orientational order on the decay of the fluorescence anisotropy in membrane suspensions. Experimental verification on unilamellar vesicles and lipid/ alpha-lactalbumin complexes. Biophys J 1984:(46) 525-539.

[88] K.A. Zachariasse, W.L. Vaz, C. Sotomayor, W. Kuhnle, Investigation of human erythrocyte ghost membranes with intramolecular excimer probes. Biochim Biophys Acta 1982:(688) 323-332.

[89] R.D. Kaiser, E. London, Location of diphenylhexatriene (DPH) and its derivatives within membranes: comparison of different fluorescence quenching analyses of membrane depth. Biochemistry 1998:(37) 8180-8190.

[90] I.A. Zainaghi, O.V. Forlenza, W.F. Gattaz, Abnormal APP processing in platelets of patients with Alzheimer's disease: correlations with membrane fluidity and cognitive decline. Psychopharmacology (Berl) 2007:(192) 547-553.

[91] J.P. Schuchardt, M. Huss, M. Stauss-Grabo, A. Hahn, Significance of long-chain polyunsaturated fatty acids (PUFAs) for the development and behaviour of children. Eur J Pediatr 2010:(169) 149-164.

[92] L.A. Horrocks, A.A. Farooqui, Docosahexaenoic acid in the diet: its importance in maintenance and restoration of neural membrane function. Prostaglandins Leukot Essent Fatty Acids 2004:(70) 361-372. 
[93] I. Carrie, G. Abellan Van Kan, Y. Rolland, S. Gillette-Guyonnet, B. Vellas, PUFA for prevention and treatment of dementia? Curr Pharm Des 2009:(15) 4173-4185.

[94] C.R. Hooijmans, A.J. Kiliaan, Fatty acids, lipid metabolism and Alzheimer pathology. Eur J Pharmacol 2008:(585) 176-196.

[95] J.H. Song, T. Miyazawa, Enhanced level of n-3 fatty acid in membrane phospholipids induces lipid peroxidation in rats fed dietary docosahexaenoic acid oil. Atherosclerosis 2001:(155) 9-18.

[96] H. Grundt, D.W. Nilsen, M.A. Mansoor, A. Nordoy, Increased lipid peroxidation during long-term intervention with high doses of n-3 fatty acids (PUFAs) following an acute myocardial infarction. Eur J Clin Nutr 2003:(57) 793-800.

[97] K. Simons, E. Ikonen, Functional rafts in cell membranes. Nature 1997:(387) 569-572.

[98] E. Kojro, G. Gimpl, S. Lammich, W. Marz, F. Fahrenholz, Low cholesterol stimulates the nonamyloidogenic pathway by its effect on the alpha -secretase ADAM 10. Proc Natl Acad Sci U S A 2001:(98) 5815-5820.

[99] P. Weber, M. Wagner, H. Schneckenburger, Microfluorometry of cell membrane dynamics. Cytometry A 2006:(69) 185-188.

[100] C. Haass, A.Y. Hung, M.G. Schlossmacher, D.B. Teplow, D.J. Selkoe, beta-Amyloid peptide and a 3-kDa fragment are derived by distinct cellular mechanisms. J Biol Chem 1993:(268) 3021-3024.

[101] P.C. Reid, Y. Urano, T. Kodama, T. Hamakubo, Alzheimer's disease: cholesterol, membrane rafts, isoprenoids and statins. J Cell Mol Med 2007:(11) 383-392.

[102] R. Ehehalt, P. Keller, C. Haass, C. Thiele, K. Simons, Amyloidogenic processing of the Alzheimer beta-amyloid precursor protein depends on lipid rafts. J Cell Biol 2003: (160) 113-123.

[103] K. Fassbender, M. Simons, C. Bergmann, M. Stroick, D. Lutjohann, P. Keller, H. Runz, S. Kuhl, T. Bertsch, K. von Bergmann, M. Hennerici, K. Beyreuther, T. Hartmann, Simvastatin strongly reduces levels of Alzheimer's disease beta -amyloid peptides Abeta 42 and Abeta 40 in vitro and in vivo. Proc Natl Acad Sci U S A 2001:(98) 5856-5861.

[104] C.A. von Arnim, B. von Einem, P. Weber, M. Wagner, D. Schwanzar, R. Spoelgen, W.L. Strauss, H. Schneckenburger, Impact of cholesterol level upon APP and BACE proximity and APP cleavage. Biochem Biophys Res Commun 2008:(370) 207-212.

[105] Paula RS, Souza VC, Benedet AL, Souza ER, Toledo JO, Moraes CF, Gomes L, Alho CS, Córdova C, Nóbrega OT. Dietary fat and apolipoprotein genotypes modulate plasma lipoprotein levels in Brazilian elderly women. Mol Cell Biochem. 2010 Apr; 337(1-2):307-15.

[106] Catalá A. Lipid peroxidation modifies the picture of membranes from the "Fluid Mosaic Model" to the "Lipid Whisker Model" Biochimie 94 (2012) 101e109. 
[107] Hoshino T, Kamino K, Matsumoto M. Gene dose effect of the APOE-epsilon4 allele on plasma HDL cholesterol level in patients with Alzheimer's disease. Neurobiol Aging. 2002 Jan-Feb;23(1):41-5.

[108] Eckert GP, Wood WG, Müller WE. Effects of aging and beta-amyloid on the properties of brain synaptic and mitochondrial membranes. J Neural Transm. 2001;108(8-9): 1051-64.

[109] Axelsen PH, Komatsu H, Murray IV. Oxidative stress and cell membranes in the pathogenesis of Alzheimer's disease. Physiology (Bethesda). 2011 Feb;26(1):54-69.

[110] E.P. Kennedy, S.B. Weiss, The function of cytidine coenzymes in the biosynthesis of phospholipides. J Biol Chem 1956:(222) 193-214.

[111] U.I. Richardson, C.J. Watkins, C. Pierre, I.H. Ulus, R.J. Wurtman, Stimulation of CDP-choline synthesis by uridine or cytidine in PC12 rat pheochromocytoma cells. Brain Res 2003:(971) 161-167.

[112] P.C. Choy, H.B. Paddon, D.E. Vance, An increase in cytoplasmic CTP accelerates the reaction catalyzed by CTP:phosphocholine cytidylyltransferase in poliovirus-infected HeLa cells. J Biol Chem 1980:(255) 1070-1073.

[113] V. Savci, R.J. Wurtman, Effect of cytidine on membrane phospholipid synthesis in rat striatal slices. J Neurochem 1995:(64) 378-384.

[114] W. Araki, R.J. Wurtman, Control of membrane phosphatidylcholine biosynthesis by diacylglycerol levels in neuronal cells undergoing neurite outgrowth. Proc Natl Acad Sci U S A 1997:(94) 11946-11950.

[115] C. Mulder, L.O. Wahlund, T. Teerlink, M. Blomberg, R. Veerhuis, G.J. van Kamp, P. Scheltens, P.G. Scheffer, Decreased lysophosphatidylcholine/phosphatidylcholine ratio in cerebrospinal fluid in Alzheimer's disease. J Neural Transm 2003:(110) 949-955.

[116] R.M. Nitsch, B.E. Slack, R.J. Wurtman, J.H. Growdon, Release of Alzheimer amyloid precursor derivatives stimulated by activation of muscarinic acetylcholine receptors. Science 1992:(258) 304-307.

[117] Pettegrew, J. W. (1989). Molecular insights into Alzheimer disease. Ann. N. Y. Acad. Sci. 568:5-28.

[118] Subbarao, K. V., Richardson, J. S., and Ang, L. C. (1990). Autopsy samples of Alzheimer's cortex show increased peroxidation in vitro. J. Neurochem. 55:342-345.

[119] Palmer, A. M., and Burns, M. A. (1994). Selective increase in lipid peroxidation in the inferior temporal cortex in Alzheimer's disease. Brain Res. 645:338-342.

[120] Farooqui, A. A., and Horrocks, L. A. (1991). Excitatory amino acid receptors, neural membrane phospholipid metabolism and neurological disorders. Brain Res. Rev. 16:171-191.

[121] F. Calon, G.P. Lim, F. Yang, T. Morihara, B. Teter, O. Ubeda, P. Rostaing, A. Triller, N. Salem, Jr., K.H. Ashe, S.A. Frautschy, G.M. Cole, Docosahexaenoic acid protects 
from dendritic pathology in an Alzheimer's disease mouse model. Neuron 2004:(43) 633-645.

[122] D.L. Moolman, O.V. Vitolo, J.P. Vonsattel, M.L. Shelanski, Dendrite and dendritic spine alterations in Alzheimer models. J Neurocytol 2004:(33) 377-387.

[123] A.C. McKee, K.S. Kosik, N.W. Kowall, Neuritic pathology and dementia in Alzheimer's disease. Ann Neurol 1991:(30) 156-165.

[124] Figure Modified Pathway central: CD40 Signaling (Fig 5), www.sabiosciences.com/ pathway.php?sn=CD40_Signaling

[125] Figure Modified Pathway central: Insulin Receptor (Fig 2), www.sabiosciences.com/ pathway.php?sn=Insulin_Receptor

[126] Figure Modified Pathway Central: CREB Pathway (Figure 3), www.sabiosciences.com/pathway.php?sn=CREB

[127] Figure Modified Pathway Central: Mito ( Figure 7), www.sabiosciences.com/pathway.php?sn=Mitochondrial_Apoptosis 
